This PDF is a selection from a published volume from the National Bureau of Economic Research

Volume Title: Labor in the New Economy

Volume Author/Editor: Katharine G. Abraham, James R. Spletzer, and Michael Harper, editors

Volume Publisher: University of Chicago Press

Volume ISBN: 978-0-226-00143-2; 0-226-00143-1

Volume URL: http://www.nber.org/books/abra08-1

Conference Date: November 16-17, 2007

Publication Date: October 2010

Chapter Title: What Do We Know About Contracting Out in the United States? Evidence from Household and Establishment Surveys

Chapter Author: Matthew Dey, Susan Houseman, Anne Polivka

Chapter URL: http://www.nber.org/chapters/c10824

Chapter pages in book: (267 - 304) 


\title{
What Do We Know about Contracting Out in the United States? \\ Evidence from Household and Establishment Surveys
}

\author{
Matthew Dey, Susan Houseman, and Anne Polivka
}

Companies choose the degree of vertical integration in the production of goods and services. In other words, they must decide what tasks to perform with in-house employees and what goods and services inputs to purchase from other entities. That mix often changes. Companies may contract out work previously done by in-house employees, or, conversely, insource work previously contracted out. While much attention has been given to the apparent growth of imported goods and services inputs-so-called offshoring or offshore outsourcing - our chapter focuses on contracting out that occurs within the United States - what we term domestic contracting out or outsourcing.

A variety of evidence has pointed to significant growth in domestic contracting out over the last two decades (Abraham 1990; Abraham and Taylor 1996; Segal 1996; Segal and Sullivan 1997; Theodore and Peck 2002). When organizations outsource tasks to a contract company, the employer of record for workers performing the tasks changes, and frequently so too does the industry in which the workers are employed. Thus, large shifts in the patterns of domestic outsourcing may affect the industry structure of employment in the economy.

Accurately measuring growth in outsourcing and the industries engaging in it, we argue, is important for understanding the changing industrial

Matthew Dey is a research economist in Employment Research and Program Development at the Bureau of Labor Statistics. Susan Houseman is a senior economist at the W. E. Upjohn Institute for Employment Research. Anne Polivka is a supervisory economist of Employment Research and Program Development at the Bureau of Labor Statistics.

This paper was prepared for the CRIW Conference on Labor in the New Economy, Bethesda, Maryland, November 16-17, 2007. The views expressed in this chapter do not necessarily reflect the policies of the Bureau of Labor Statistics or the views of other BLS staff members. 
structure of employment in the U.S. economy, constructing and interpreting sectoral productivity statistics, assessing the role outsourcing plays in adjustment mechanisms, and understanding its implications for workers and a variety of labor market policies. Yet, the phenomenon is not well documented. In this chapter, we pull together a variety of evidence on the extent of and trends in domestic outsourcing, the occupations in which it has grown, and the industries engaging in outsourcing to the employment services sector, which has been a particularly important area of domestic outsourcing. In addition, we examine evidence of the contracting out of selected occupations to other sectors. We point to many gaps in our knowledge on trends in domestic outsourcing and its implications for employment patterns and to inconsistencies across data sets in the information that is available.

An innovation of this chapter is the development of data on occupation by industry, which we use to examine trends in certain types of domestic outsourcing and their effect on employment patterns. When a manufacturer, for example, utilizes a staffing agency to fill clerical and production jobs, outsources information technology (IT) work to a firm providing computer services, and outsources transportation work to a trucking company, the number and occupational distribution of workers classified in the manufacturing sector change, even if the number and occupational distribution of workers performing the tasks do not. Exploiting the fact that changes in the industry distribution of occupational employment often accompany outsourcing, we construct occupation-by-industry panel data from the Occupation Employment Statistics program (OES), which we then use to shed light on the recent growth in various types of domestic outsourcing, including, but not limited to, contracting out to the employment services sector.

The large growth of the employment services sector since the 1980s has been among the most visible examples of domestic contracting out, and thus the first part of our chapter focuses on this case. Two industries, temporary help services and professional employer organizations (PEO), account for almost all employment in this sector, and in each industry virtually all employees are assigned to other sectors as contract workers. We compare evidence from several household and establishment surveys - the Current Population Survey (CPS), the Contingent Worker Supplement to the CPS (CWS), the Occupational Employment Statistics program (OES), the Current Employment Statistics program (CES), and the Economic Census-on levels of and trends in the employment, in the occupational distribution of employment, and in the industries to which these workers are assigned for the employment services sector as a whole and for the temporary help and PEO industries separately.

Although data on contracting out to the employment services sector is rich relative to other types of contracting out, the information from these data is often inconsistent. We note discrepancies among household and establish- 
ment surveys on levels and trends in employment, trends in occupations, and industries to which workers in this sector are assigned, and we discuss possible reasons for these differences. Particularly problematic is the PEO industry, which was broken out as a separate industry with the introduction of the new industry classification system, North American Industrial Classification System (NAICS), in the late 1990s and early 2000s. Differences in state laws governing the classification of PEO employment and large discrepancies between PEO employment figures from the CES and the Economic Census render it difficult to assess even basic employment levels and trends for this emerging industry.

New evidence that we present from the OES suggests greater growth in the outsourcing of certain occupations than has been apparent from household data. In particular, the OES shows much stronger growth in the employment of blue-collar occupations within the employment services sector than has been evident in either the CPS or the CWS data. We also use OES data to detect evidence of outsourcing of other occupations to other industrial sectors. As a starting point, we examine trends in the industry distribution of the most prevalent occupations among individuals identified as working for a contract company in the five waves of the CWS. In results that parallel our findings for employment services, we report evidence of growth in contracting out for several occupations in the OES data, although the CWS shows little evidence of an increase in contract workers.

\subsection{Importance of Documenting Domestic Outsourcing}

Interest in documenting domestic outsourcing is motivated by several factors. One is the apparently large role that contract companies, especially temporary help agencies, play in the adjustment to business cycles. Temporary help employment is considerably more variable than other forms of employment (Golden 1996; Segal and Sullivan 1995, 1997; Theodore and Peck 2002), and, it has been hypothesized, firms increasingly use contract workers to accommodate uncertainty and flux in input and product markets (Abraham 1988; Abraham and Taylor 1996; Davis-Blake and Uzzi 1993; Golden and Appelbaum 1992; Houseman 2001). Reasons for this greater reliance on contracting out include reduction in hiring and recruiting costs and the elimination or reduction of layoffs by client companies, which, in turn, may reduce companies' unemployment insurance costs or their exposure to unjust dismissal lawsuits (Autor 2003; Dertouzos and Karoly 1992; Hachen 2004; Lee 1996; Masters and Miles 2002; Mehta and Theodore 2001; Polivka 1996a).

Adjustment of contract workers also may be used in lieu of adjusting workers' hours and inventories in response to changes in demand (Abraham and Taylor 1996). Firms adjust workers' hours and inventories in response to fluctuations in product demand, and thus changes in workers' hours and 
inventories are followed closely as indicators of the health of the economy (Hamermesh 1993; Hart 1984; Topel 1982). To the extent that the use of contract workers supplements or replaces these other adjustment mechanisms, accurate measurement and analysis of domestic contracting out will provide a more complete understanding of business cycle dynamics.

Economists, policymakers, and analysts who study changes in the industrial structure of output and employment also need to be aware of the effect of contracting out on their measures. If organizations outsource tasks to a contract company, the employer and, typically, the industry of record for the workers performing the tasks change. Consequently, rapid growth and widespread use of contract workers can distort measurement of changes in the U.S. industrial structure and employment trends in specific industries (Dey, Houseman, and Polivka 2008; Estavaõ and Lach 1999a, 1999b; Segal and Sullivan 1997). Furthermore, statistics that depend on the complete enumeration of employees working in an industry, such as sectoral labor productivity measures, can be biased if appropriate account of contract company workers is not taken (Dey, Houseman, and Polivka 2008; Estavão and Lach 1999a).

In addition, contracting out has potentially important implications for workers and labor market policy. Contracting out could serve to increase the probability of workers obtaining employment, but it also could reduce longrun job security. With respect to the first consideration, contract companies, particularly temporary help agencies, may facilitate the matching of workers and employers. Efficiencies may arise if contract companies are better able to recruit workers with specialized skills or guarantee continuous employment to workers in occupations or sectors of the economy subject to widely fluctuating demands for workers (Erickcek, Houseman, and Kalleberg 2003; Houseman 2001; Krueger 1993; Segal and Sullivan 1997; Theodore and Peck 2002). In addition, efficiencies may arise if employers are better able to screen workers from contract companies prior to placing them on the payroll as part of their permanent staff, and if contract companies provide some form of training and testing, such as instruction in and testing of knowledge about standardized computer programs that might be otherwise unknown to potential employers or more costly for them to provide (Abraham 1990; Autor 2001; Autor, Levy, and Murnane 1999; Houseman 2001; Kalleberg, Reynolds, and Marsden 2003; Lenz 1996; Segal and Sullivan 1997). At the same time, by reducing the costs of job matching, contract companies may also lower the costs of termination, resulting in less job security. Some evidence suggests that contract employment is associated with lower job security, as manifested through decreased job tenure and reduced opportunities for advancement (Houseman and Polivka 2000; Segal and Sullivan 1997).

Use of contract workers also may reduce wage pressures in tight labor markets (Houseman, Kalleberg, and Erickcek 2003). If workers face costs for switching employers, then market forces primarily will affect the wages of 
new hires. In turn, if internal labor market rules influence the wages of both new hires and those with greater tenure, or if internal labor markets reduce wage differentials across skill levels within establishments, then contract companies may be able to pay new hires or workers in noncore services a lower wage rate than establishments would pay if they hired these workers directly. Alternatively, in particularly tight labor markets, contract companies may permit establishments to pay workers who have been newly hired or who have specialized skills a higher wage than incumbent workers. Thus, they would provide a mechanism for establishments to exert greater restraint on wage increases for incumbent workers. Both more efficient matching of workers and lower wage rates may serve to increase the demand for workers and thereby reduce unemployment rates. Indeed, Katz and Krueger (1999) present evidence that states with a greater supply of temporary-help employment in the late 1980s experienced lower wage growth in the 1990s. They also estimate that the lower wage growth associated with this increase in the supply of temporary-help employment may have accounted for up to a 0.39 percentage-point reduction in the NAIRU (the nonaccelerating-inflation rate of unemployment, or the rate of unemployment consistent with stable inflation) throughout the 1990s.

Moreover, although much of domestic outsourcing may be motivated by firms' desire to tap into the expertise of a contract company, organizations may outsource as a mechanism to avoid unions or workplace safety regulations, to reduce health insurance and pension costs, to economize on compensation and benefit costs by differentially offering compensation packages, and to lower unemployment insurance costs (Abraham and Taylor 1996; Davis-Blake and Uzzi 1993; Erickcek, Houseman, and Kalleberg 2003; Government Accountability Office [GAO] 2006; Hachen 2004; Houseman 1998, 2001; Lautsch 2002; Mehta and Theodore 2001; Mehta et al. 2003; Segal and Sullivan 1997). Indeed, in response to some of these concerns, fourteen states changed the legal status of workers employed through professional employer organizations to preclude companies from circumventing unemployment insurance and workers' compensation costs through this form of outsourcing.

Each of these reasons underscores the importance of better understanding domestic outsourcing. Establishing the basic magnitude of and trends in contracting out is the first step in developing this understanding.

\subsection{Data Sources and the Construction of Industry-occupation Data from the OES}

Although developments in contracting out have potentially important implications for macroeconomic, industry, and labor market analysis and policy formation, information on contracting out is scant. We draw upon data from several government, establishment, and household surveys to shed 
more light on trends in various types of contracting out in the United States and to examine the consistency of evidence on contracting out among data sets. We use data from the Current Employment Statistics (CES) program to examine industry employment trends, to compare trends in CES data with those observed in the Economic Census, and to benchmark employment estimates in the construction of an industry-occupation data set, described later. The CES is a monthly establishment survey conducted by state employment security agencies in cooperation with the Bureau of Labor Statistics. Each month the CES program surveys approximately 150,000 businesses and government agencies, representing approximately 390,000 individual work sites, in order to provide detailed industry data on employment, hours, and earnings of workers on nonfarm payrolls. While the CES is a monthly survey of a nationally representative sample of establishments, the Economic Census, conducted every five years by the U.S. Census Bureau, is a comprehensive survey of establishments in most industries. ${ }^{1}$ We report Economic Census data collected from professional employer organizations on the industries to which they assign workers, and we compare Economic Census estimates on PEO employment to those of the CES.

We also draw upon data from the Current Population Survey (CPS), a nationally representative, monthly survey of approximately 60,000 households collected by the U.S. Census Bureau under the auspices of the Bureau of Labor Statistics. Every month the CPS collects labor market, demographic, and job-related information on approximately 110,000 individuals aged sixteen and older. We use the CPS to examine trends in employment and in employment by occupation within the employment services sector.

In addition to the basic CPS, we use data from the Contingent Worker Supplements (CWS) to the CPS to examine employment levels and occupational patterns of workers in temporary help services and in other types of contract companies. The CWS was designed to obtain an estimate of the number of workers in contingent or alternative work arrangements. In that supplement, a contingent arrangement is defined as any job in which an individual does not have an explicit or implicit contract for long-term employment (and thus for economic reasons the arrangement is not expected to be long-term), and an alternative work arrangement is defined as employment that is arranged through an employment intermediary or a work arrangement whose place, time, and quantity of work are potentially unpredictable. The CWS measures workers in four such alternative work arrangements, including workers paid by temporary help firms and those whose employment is arranged by a contract company. The CWS was conducted five times between February 1995 and February 2005. All employed individuals except unpaid family workers were included in the supplement. Consequently, the CWS collected

1. Government, agriculture, forestry and fisheries, scheduled commercial airlines, railroads, schools and colleges, political and religious organizations, private household employees, and establishments with no paid employees are excluded from the survey. 
information on approximately 69,000 individuals each February or 344,000 individuals when all five years are combined. For individuals who held more than one job during the survey reference week, the questions referred to the characteristics of the job in which they worked the most hours.

\subsection{Industry-occupation Data Set Construction}

A principal innovation of our chapter is the construction of longitudinal data on occupation by industry from the Occupational Employment Statistics (OES) program, which we use to examine changes in the industry structure of employment within occupations and to shed light on trends in selected areas of contracting out. The OES program, operated by the Bureau of Labor Statistics (BLS), generates employment and wage estimates by detailed occupations. In its current form, the OES program surveys approximately 200,000 establishments semiannually (in May and November) and collects wage and employment information for each occupation employed by the establishment. By collecting payroll information for a relatively large number of establishments, the OES program allows precise estimation of industry-occupation employment levels at the national level.

Although the OES program has operated since 1988, thereby allowing a rather extensive time series analysis, the program has undergone numerous changes in the data collection procedure and the coding of industries and occupations that complicate the construction of a consistent industryoccupation employment time series. ${ }^{2}$ A necessary result is that some of the industry and occupation detail that is a great strength of the cross-sectional data must be suppressed in the time series data. With this fact in mind, we estimate employment levels for eighteen broad and an additional six narrow occupation groups and for sixteen sectors from 1989 to $2003 .{ }^{3}$

\subsubsection{Data Before 1996}

Prior to 1996, the OES program collected occupational employment data for selected industries in one year of a three-year survey cycle. For example, manufacturing establishments were surveyed in 1989, 1992, and 1995, while establishments in the service sector, including employment services, were surveyed in 1990 and 1993. These data were designed to yield accurate, periodic estimates of staffing patterns within industries but were not specifically designed to yield comparisons of the occupational structure across industries. To examine changes in occupational structure over time in the pre-1996 period, we combine three years of OES data and assume that the occupational distribution of employment within an industry remains constant over a three-year period. For example, we combine OES data from

2. The predecessor program on which OES was based started in the early 1970s. The early program, however, did not cover all industries and only aggregate state estimates were generated.

3. Abraham and Spletzer (2007) also construct an occupation-by-industry time series data set from the OES using a methodology similar to the one that we developed. 
1988 to 1990 to estimate the occupational distribution of employment for each industry in 1989, we combine OES data from 1989 to 1991 to estimate the occupational distribution of employment for each industry in 1990, and so forth. For any particular year, the estimates of the occupational distribution of employment within an industry will be based on an OES survey of the industry that was conducted in that year, in the previous year, or in the following year. Because we use these early OES data primarily to examine trends in the occupational distribution of employment across industries over long (ten-to-fifteen year) time horizons, the assumption inherent in our data construction for these early years should not unduly affect our results.

To construct estimates of industry-occupation employment in any given year from 1989 to 1995, we benchmark the OES data to each sector's employment levels as measured in the CES in the specified year. During this period, the OES was conducted once a year, primarily in May. ${ }^{4}$ To generate estimates of the number of employees in a specific occupation within an industry in a particular year, we multiply the industry total employment in that year (as measured by the CES) by the share of employment in that occupation (as measured in the OES). ${ }^{5}$ More formally, we estimate employment in occupation group $i$ and sector $j$ in year $t$ (where $t$ runs from 1989 to 1995), $\hat{E}_{i j t}$, according to the equation

$$
\hat{E}_{i j t}=E_{j t}^{c} \times\left(\frac{E_{i j s}^{o}}{E_{j s}^{o}}\right),
$$

where $s \in\{t-1, t, t+1\} ; \mathrm{E}_{j t}^{c}$ is CES employment in sector $j$ and year $t ; E_{i j s}^{o}$ is the employment level in occupation group $i$ and sector $j$ in year $s$ reported by the OES program; and $E_{j s}^{o}=\sum_{t} E_{i j s}^{o}$ represents OES employment in sector $j$ in year $s$. Therefore, $\left(E_{i j s}^{o} / E_{j s}^{o}\right)$ is the share of employment in occupation $i$ in sector $j$ in year $s$ as measured in the OES data, which we assume not to vary significantly in the short run. In this way, we generate estimates of employment by occupation for each sector in each year for the purpose of examining shifts in the pattern of occupational employment across industries over relatively long time horizons.

\subsubsection{Data from 1996 Forward}

Beginning in 1996, the OES program adopted a three-year sampling scheme that allows the estimation of employment and wage levels for

4. Benchmarking to the CES helps minimize sampling error, which is inherent in the random component of the OES sample design. In addition, such benchmarking is necessary for the years from 1989 to 1995 because the OES data were not collected for each industry in each year.

5. The reference month for OES data prior to 1996 is May, while the reference month from 1996 to 2002 is November. Beginning in 2003, the OES collects data in both May and November. In order to have a consistent time series we choose to benchmark to November CES data for all years. An examination of recent OES data shows that there are no systematic seasonal (May versus November) differences in the occupation distribution of the employment services sector so our estimates should not be particularly sensitive to our decision to benchmark to November CES employment totals. 
narrowly defined geographic regions, industries, and occupations. Over a three-year period, the OES samples and contacts approximately 1.2 million establishments (about 400,000 establishments per year), with each industry surveyed in every year. Although the OES has been designed to produce estimates using the full three years of the sample, we only produce national estimates at a fairly aggregated occupation and industry level, and thus, for our purposes, we can use a single year of data from the OES. The OES generates official estimates using three years of data combined; however, when generating employment estimates at the national level for fairly aggregated industry and occupational categories, as we do, use of data from a single year has some advantages over combining data from three years. The annual sample sizes are sufficient to generate fairly precise estimates within broad industry and occupation categories, and for cyclically sensitive and dynamic industries, like employment services, the occupational distributions can significantly change over a three-year period.

Specifically, for the years 1996 to 2004 we estimate employment by occupation by sector according to the following formula:

$$
\hat{E}_{i j t}=E_{j t}^{c} \times\left(\frac{E_{i j t}^{o}}{E_{j t}^{o}}\right) .
$$

As for the years prior to 1996, we benchmark all sector employment numbers to the not-seasonally-adjusted November employment figures in the CES. ${ }^{6}$ The only conceptual difference between our industry-by-occupation employment estimates beginning in 1996 and estimates constructed for the pre-1996 period is that starting with 1996 the occupational share of employment within each sector always comes from OES data collected for the same year.

\subsubsection{Occupation Classification}

From 1988 to 1998, the OES characterizes occupations by its own system of codes. Beginning in 1999, the OES characterizes occupations by a modified version of the Standard Occupational Classification (SOC) system. Therefore, we need to define a system that links OES occupation codes to SOC codes. While many OES occupations have a unique counterpart in the SOC system, a number of occupations (including those in the "All Other" category) do not have a unique match. Since our goal is to construct a time series of industry-occupation employment, we choose to aggregate occupations into rather broad categories, thereby minimizing the effect of the break

6. In 2003 the OES shifted from an annual survey of approximately 400,000 establishments conducted in November to a semiannual survey of approximately 200,000 establishments conducted in May and November. We combine May and November OES samples to compute occupation shares within sectors, and, for comparability to the earlier years, we continue to benchmark sector employment totals to the not-seasonally-adjusted November CES figures. The occupation shares of industry employment calculated from OES data use OES sample weights related to the establishment's probability of selection. 
in the classification system after 1998 . We also constructed time series data for six occupations that we identified as commonly outsourced. Appendix table 7A.1 presents our eighteen broad occupation groups.

\subsubsection{Industry Classification}

From 1988 to 2001, the OES characterized industries by the Standard Industrial Classification (SIC) system. Beginning in 2002, the OES characterizes industries according to the North American Industrial Classification System (NAICS). Therefore, we need to define a system that links SIC codes to NAICS codes. Although a comprehensive linkage system has been developed, various problems complicate this task. First, from 1988 to 1995, we do not have establishment-level data, but only have access to employmentby-occupation and three-digit SIC code. This is problematic since the SICNAICS crosswalk has been developed at the four-digit SIC level, and the aggregation into three-digit industries does not necessarily lead to a unique NAICS match. In addition, even with the most detailed level of SIC and NAICS codes, there are many cases for which the link is not one-to-one. For these reasons, we chose to substantially aggregate industries (roughly into sectors) with the exception of the employment services industry. While this aggregation is not perfectly clean (there are three-digit SIC codes that map into multiple sectors), it eliminates a large majority of the problems and allows a relatively consistent definition of industries over time. In addition, because we are weighting the underlying OES data in a manner to match CES employment estimates, our industry definitions allow the more or less direct use of the published estimates and are therefore consistent with the time series properties of the CES data. Appendix table 7A.2 presents our sixteen industries.

\subsection{Employment Services}

The growth of the employment services sector over the last two decades represents one of the most visible cases of domestic outsourcing. Under the NAICS classification, the employment services sector is composed of three industries: employment placement agencies, temporary help services, and professional employer organizations (PEOs). ${ }^{7}$ According to CES estimates, temporary help services accounts for the bulk of employment in the employment services sector, representing 72 percent of employment in 2006. Professional employer organizations, with 19 percent of sec-

7. Under the 2007 NAICS, executive search services was moved out of the Human Resources consulting services industry into the employment services industry and the five-digit NAICS industry's name was changed to Employment placement agencies and executive search services. The placement of executive search services into this five-digit NAICS industry had a minimal impact on the number of employees in the five-digit industry and no discernable effect on the distributions discussed in the text. 
tor employment in 2006, account for most of the remaining employment in the sector. ${ }^{8}$

Employment placement agencies, which according to CES data accounted for just 8 percent of the sector's employment in 2006, help place individuals into permanent jobs. Those they assist do not appear on the payroll of the employment placement agency. In contrast, while temporary help agencies and PEOs also place workers into jobs with client organizations, workers are paid by the temporary placement agency or PEO, and they generally appear in the employment statistics as workers in that industry, not in the client industry, where they perform tasks. Temporary help services place individuals into jobs at the work site of client organizations on a temporary basis, though the duration of such temporary placements varies considerably. Companies use temporary help agencies to staff positions for a variety of reasons, including the need to handle seasonal work or a temporary increase in product demand, to fill in for temporary absences of permanent staff, or to screen workers for permanent jobs (Abraham 1988; Autor 2001, 2003; Autor, Levy, and Murnane 1999; Houseman 2001; Kalleberg, Reynolds, and Marsden 2003; Ono and Sullivan 2006; Segal and Sullivan 1997).

Owing to their growth, PEOs, which had been grouped with temporary employment services in help-supply services in the SIC industry codes, were broken out as a separate industry category in the NAICS. Professional employer organizations specialize in human resource (HR) management, and they offer companies a wide variety of services. Many companies use PEOs for routine HR activities such as payroll processing, design and administration of employee benefit programs, payroll tax withholding and filing, record keeping, payment of unemployment insurance taxes, administration of disability and workers' compensation programs, and development and administration of employment policies in accordance with state and federal workplace regulations (Katz 1999). However, many companies also use PEOs for "human capital enhancing services" such as recruiting, the development and implementation of employee training programs, and the management of employees' evaluation and companies' performance reward programs (Klass et al. 2005).

Professional employer organizations and temporary help agencies often have the status of co-employers with the client company. The client company typically maintains primary responsibility for managing employees' onsite tasks and the provision of materials, supplies, and equipment to employees.

8. As will be discussed later, the QCEW on which the CES is based has some PEO workers reassigned to the PEO clients' industries. This reassignment could distort the proportion of employment services in the three subindustries. The Economic Census does not reassign PEO workers out of the employment services sector. In the 2002 Economic Census, temporary help services accounted for 57 percent, PEOs for 40 percent, and placement agencies for 3 percent of employment in employment services. Consequently, even based on Economic Census estimates, temporary help services and PEOs account for more than 90 percent of employment in the employment services sector. 
The PEOs and temporary help agencies typically assume many of the legal responsibilities for the employees who work at their clients' locations, including the responsibility to comply with various government regulations. The Internal Revenue Service (IRS) considers the PEO and the temporary help agency to be the employer of record, and as such these staffing agencies are liable to pay trust fund income and unemployment taxes (Houseman 1998; Katz 1999).

In the temporary help services and PEO industries, which account for over 90 percent of employment in the sector, workers are assigned to client organizations and do not perform work in the employment services sector. Permanent staff of temporary help agencies represent only an estimated 3 percent of employment in that industry, while administrative staff of PEOs account for only about 1 percent of employment in that industry. ${ }^{9}$ Thus, in two of the three industries in employment services, which represent the overwhelming majority of workers in the sector, almost all are assigned to client organizations. In this sense, the temporary help services and PEO industries are contract sectors, and the growth of employment in these industries is a good measure of a certain type of outsourcing. Drawing in part on new data developed from the OES, we examine for the employment services sector and its component industries estimates of employment levels and trends, the occupational distribution of employment, and the industries to which these workers are assigned. In several cases we note significant discrepancies in the evidence among surveys.

\subsection{Overall Employment Levels in Employment Services and its Component Industries}

The CES is the source typically cited for estimates of employment in employment services. However, information on monthly employment in employment services also may be derived from the Current Population Survey, which collects data on industry for employed individuals' primary and secondary jobs. ${ }^{10}$ Estimates of employment in the temporary help industry are available from the five Contingent Worker Supplements. In addition, estimates of employment in employment services and each of its component industries are available from the Economic Censuses, which are conducted every five years. Comparisons across these various sources reveal large discrepancies in the employment levels in employment services and its component industries-discrepancies that, for the most part, cannot

9. Estimates of the fraction of total industry employment that is administrative staff come from the U.S. Bureau of Labor Statistics (1988) for the temporary help agencies and from Economic Census estimates for the PEO industry.

10. Data on multiple jobholders' second job are only collected in the CPS for a subset of individuals surveyed in any given month (primarily those individuals residing in a household being interviewed for the fourth or eighth time). 
be explained by differences in the samples or in the construction of the statistics.

We begin by comparing employment estimates for all of employment services and for the temporary help industry from the CES with those from the CPS or the Contingent Worker Supplement of the CPS. To make estimates from the CPS as comparable as possible to those from the CES, we exclude the self-employed, unpaid family workers, and farm workers from our sample of CWS and CPS workers. Figure 7.1 shows the percentage of the employed who report being paid by a temporary help agency in each of the five waves of the CWS, along with the percentage of paid, nonfarm workers in the corresponding February CPS who work in employment services, and the not-seasonally-adjusted percentage of nonfarm payroll employment in employment services and temporary help services in the same months from the CES. Comparing employment services figures in the CES and the basic CPS, it is apparent that not only is the share of employment in employment services as measured in the CPS less than half that in the CES, but the strong upward trend apparent in the CES is almost entirely absent in the CPS.

The Contingent Worker Supplements were intended to correct what was believed to be substantial underreporting of temporary help employment in the basic CPS, which occurs in part because respondents often report the client for whom they are assigned to work as their employers. In the CWS, respondents were specifically asked whether they were paid by a temporary help agency, and this question seems to have helped identify additional temporary help workers. Although all of those who reported being paid by a temporary help agency in the CWS should also have been coded as employment services workers in the basic CPS of that survey, slightly under half, in fact, were coded in the broader industry. This finding supports the belief that workers in employment services are underreported in the basic CPS. ${ }^{11}$

In addition to examining the percentage of those identified as paid by temporary help agencies in the CWS who are classified in employment services, we compute the overlap in the reverse direction: the percentage of those classified in the employment services sector of the basic CPS who subsequently identify themselves as being paid by temporary help agencies in the CWS. This exercise provides further evidence of the difficulty in the basic CPS of classifying workers as being in the employment service sector based on respondents' description of their employers. ${ }^{12}$ Because workers

11. In general across the time period we observed, the CES measured a larger number of wage and salary workers in the nonagricultural sector than did the CPS. However, the difference in these aggregate employment measures were relatively slight (approximately 1.1 percent) in comparison to the difference observed for Employment Services between the CES and the CWS.

12. In the basic CPS an individual's industry of employment is determined through the provision of the name of the employer for which an individual works and an inquiry about the industry of this employer. The inquiry about the industry in the basic CPS includes the following question, which interviewers are instructed to read if necessary for clarifying the nature of the work: "What do they make or do where you work?" This instruction could prompt some 


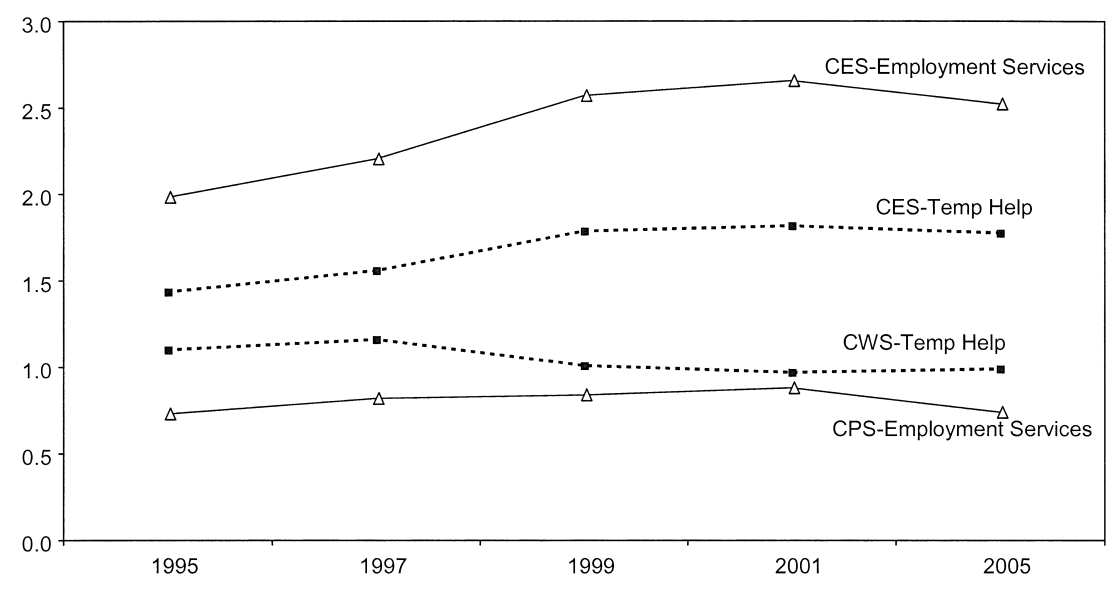

Fig. 7.1 Employment services and temporary help services employment, CES vs. CPS and CWS measures (percent of nonfarm payroll employment, February)

Source: Authors' calculations based on February CPS, CWS, and CES (not seasonally adjusted) data. Self-employed and farm workers were excluded from calculations in the CPS and CWS samples to make them as comparable as possible to the CES sample.

who were coded in employment services in the basic CPS could have been employed with a PEO or in an employment placement agency, not all would be expected to answer that they were paid by a temporary help agency in the CWS. Nevertheless, the fact that across all five waves only about half of those classified in employment services in the basic CPS were coded as temporary agency workers in the accompanying CWS is surprising given that, according to CES figures, temporary help workers accounted for over 70 percent of employment services employment throughout the period.

Estimates of the percentage employed in temporary help agencies from the Contingent Worker Supplements to the CPS and from the CES are more similar than estimates of the percent employed in all employment services in the CPS and the CES, but the CES estimates for the share in temporary help employment still are considerably larger than those derived from the CWS and display a different trend. Whereas the share of employment in temporary help rises through the 1990s in the CES, it falls in the late 1990s in the CWS and, as a result, the gap between the CES and CWS estimates widens over the period. ${ }^{13}$

respondents employed by temporary help agencies to describe the activities at the places where they are assigned to work and thus lead to a misclassification of their industries in the basic CPS. In addition, some individuals employed by temporary help agencies may be unclear about which name to provide as their employer.

13. The CPS and CWS figures represent the fraction of workers whose primary job is in the industry, whereas the CES statistics are computed as a fraction of all jobs (Cohany 1996; Polivka 1996b). Our examination of second jobs in the basic CPS shows that this difference probably accounts for little of the difference between the basic CPS and CES estimates of the 
Whereas the CES suggests a considerably larger number of workers are employed in employment services than does the CPS, data from the Economic Census yield even higher estimates of employment in employment services and in the major component industries, temporary help, and PEOs, as can be seen from the estimates presented in table 7.1. The 1992, 1997, and 2002 Economic Census figures for the employment services sector have consistently been about a third higher than CES figures for the same industry and time period. Although employment estimates in the small employment placement agency industry have been higher in the CES than in the Census figures, the opposite has been the case in the other two industries and the differences have been substantial, particularly in the PEO industry. In 1992 and 2002 the employment estimates for PEOs in the Economic Census were more than double those in the CES. While both the Economic Census and the CES estimates show PEO employment increasing almost fivefold between 1992 and 2002, PEO workers constituted 1.5 percent of all wage and salary nonagricultural employment in 2002 in the Economic Census estimates but only 0.7 percent in the CES estimates.

As we will discuss later, although differences in the treatment of PEO workers in the two surveys potentially could explain these discrepancies, we find that they account for little of the difference between the CES and the Economic Census estimates in the time period we are considering. The Economic Census is collected through a mail survey that is sent to employers once every five years. The Economic Census' definition of a paid employee is the same as that used by the Internal Revenue Service on Form 941. The CES draws its sample from the Quarterly Census of Employment and Wages (QCEW), based on the industry and employment characteristics reported to the QCEW. In addition, the CES industry estimates are benchmarked to the QCEW once a year, with the discrepancy between the CES and the QCEW being distributed throughout the year. The QCEW employment figures are derived from employers' quarterly reports to the State Employment Security agencies. In these reports, employers that are covered by state Unemployment Insurance (UI) filing rules provide their total UI-covered employment in each month of the quarter and the total quarterly wages for all covered employees. ${ }^{14}$

Under their Unemployment Insurance filing rules, several states require PEOs to report their clients' employment and wages in separate unemployment insurance accounts and to assign the industry of the client to these

share of employment-services employment reported in figure 7.1. No data on second jobs is collected in the CWS, and thus we are unable to assess its importance in those data. Discrepancies in the reporting of temporary help employment between the CWS and the basic CPS of the same survey, discussed earlier, suggest that some of the difference between measures derived from the CPS and those from the CES results from problems with the accuracy of information provided by household respondents.

14. The CES estimates for March and the QCEW estimates for the third month of the first quarter were quite similar for the years we compared to the Economic Census. 


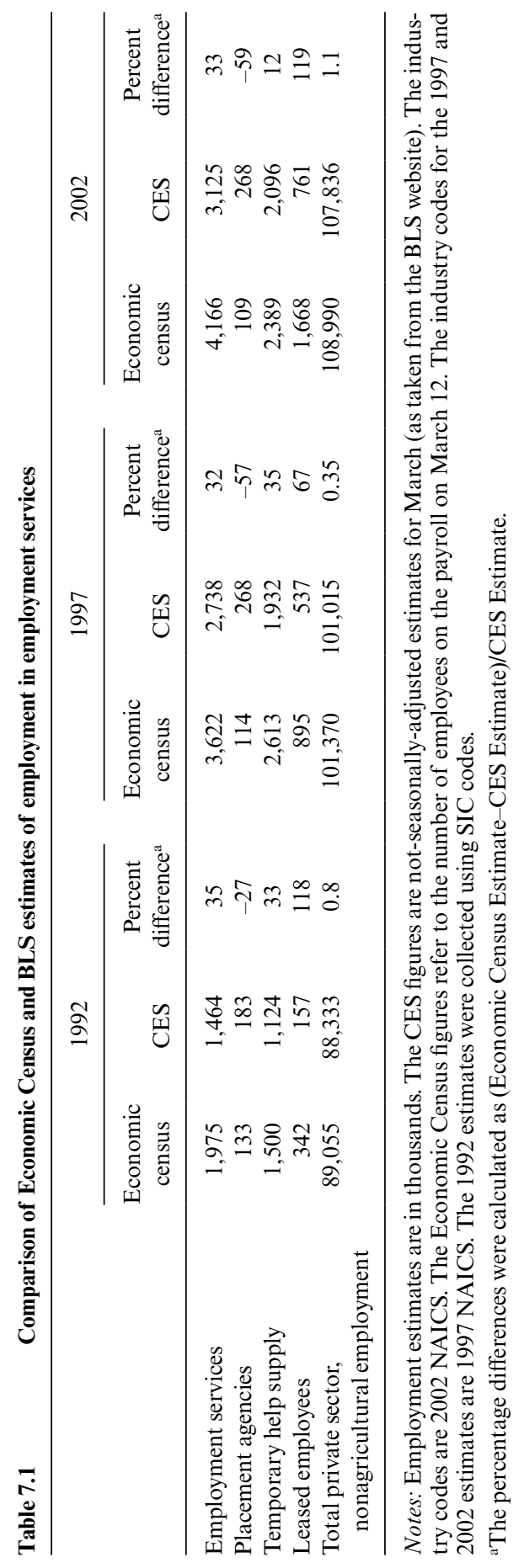


accounts. This requirement should remove the client's employment from the estimates of PEO employment. Several other states require PEOs to file multiple work site reports. Under this requirement, PEOs are requested to file a separate work site report for each of their customers, providing the customers' employment, wages, and industry. If a multiple work site report is filed by a PEO, the QCEW staff assigns the PEO's employment and the industry of that employment based on this report. This again would reduce the amount of employment in the PEO industry.

In 2002, fourteen states required PEOs to report employment using an Unemployment Insurance account for the client, and another twenty states required PEOs to file a separate work site report for each of their customers. ${ }^{15}$ Thus, QCEW PEO employment, and correspondingly CES PEO employment, should be less than Economic Census PEO employment in states with these regulations. Furthermore, if the reassignment of PEO employment in the QCEW to a client's industry were complete, the QCEW's measurement of PEO employment should be approximately 1 to 2 percent of the Economic Census figures, based on 1997 Economic Census estimates that 1.3 percent of $\mathrm{PEO}$ employees were involved in the management of the $\mathrm{PEO}$ and hence were not assigned to a client firm. Table 7.2 presents the average ratio of QCEW PEO employment to Economic Census PEO employment in 2002 for forty-five states and the District of Columbia combined ${ }^{16}$ it also presents the average ratio among states within each reporting requirement category. The three categories include the following: (a) states requiring PEOs to report their clients' employment using a separate unemployment insurance account, (b) states mandating a multiple work site report, and (c) states with no such reporting requirement. Figure 7.2 presents similar information for each state separately, with the ratio of the QCEW employment to Economic Census employment on the $y$-axis and the natural logarithm of Economic Census employment on the $x$-axis. ${ }^{17}$ This graph provides a picture of the variability of the ratio among states with the same reporting requirements and across states with different reporting requirements.

The ratios reported in table 7.2 and figure 7.2 indicate that state UI reporting requirements for PEOs can account for only some of the difference in the QCEW and Economic Census estimates of PEO employment. The average

15. The fourteen states requiring PEOs to report employment using the clients' Unemployment Insurance accounts were Alaska, Connecticut, Delaware, Iowa, Kentucky, Maine, Massachusetts, Minnesota, Mississippi, Nebraska, Rhode Island, South Carolina, South Dakota, Tennessee, and Vermont. The states requiring PEOs to file a separate work site report for each client were Alabama, California, Colorado, Florida, Georgia, Kansas, Louisiana, Montana, Nevada, New Hampshire, New Jersey, New York, North Carolina, North Dakota, Ohio, Oklahoma, Oregon, Utah, Virginia, and West Virginia.

16. Four states were not included in the analysis because the Census Bureau did not release the information to the public owing to confidentiality constraints. In addition, Montana was excluded from the analysis because the ratio of the QCEW's measure of PEO employment to the Economic Census measure of PEO employment was over seven and thus the inclusion of Montana in the analysis unduly influenced some of the averages.

17. The natural log was used for the $x$-axis solely to improve the appearance of the graph. 


\begin{tabular}{|c|c|c|c|c|}
\hline & All states & $\begin{array}{l}\text { Required to file } \\
\text { under client's } \\
\text { unemployment } \\
\text { insurance }\end{array}$ & $\begin{array}{l}\text { Multiple work site } \\
\text { report mandated }\end{array}$ & $\begin{array}{l}\text { No state } \\
\text { requirements }\end{array}$ \\
\hline Ratio & 0.43 & $0.20^{\mathrm{a}}$ & 0.43 & 0.61 \\
\hline $\begin{array}{l}\text { Percent with ratio less than } \\
0.05 \text { (QCEW employment } \\
\text { less than } 5 \% \text { of EC) }\end{array}$ & 13.3 & 25.0 & 11.1 & 6.7 \\
\hline $\begin{array}{l}\text { Percent with ratio greater than } \\
1 \text { (QCEW employment } \\
\text { more than } 100 \% \text { of EC) }\end{array}$ & 6.7 & 0.0 & 5.6 & 13.3 \\
\hline
\end{tabular}

${ }^{\text {a In }}$ a regression using the ratio as the dependent variable and dummy variables indicating whether a state required filing under a client's UI or a state-mandated multiple work site report as control variables, the coefficient on the control variable indicating that a state required filing under a client's UI was statistically significant at the 1 percent level. The mandatory work site control variable was not statistically significant at standard levels.

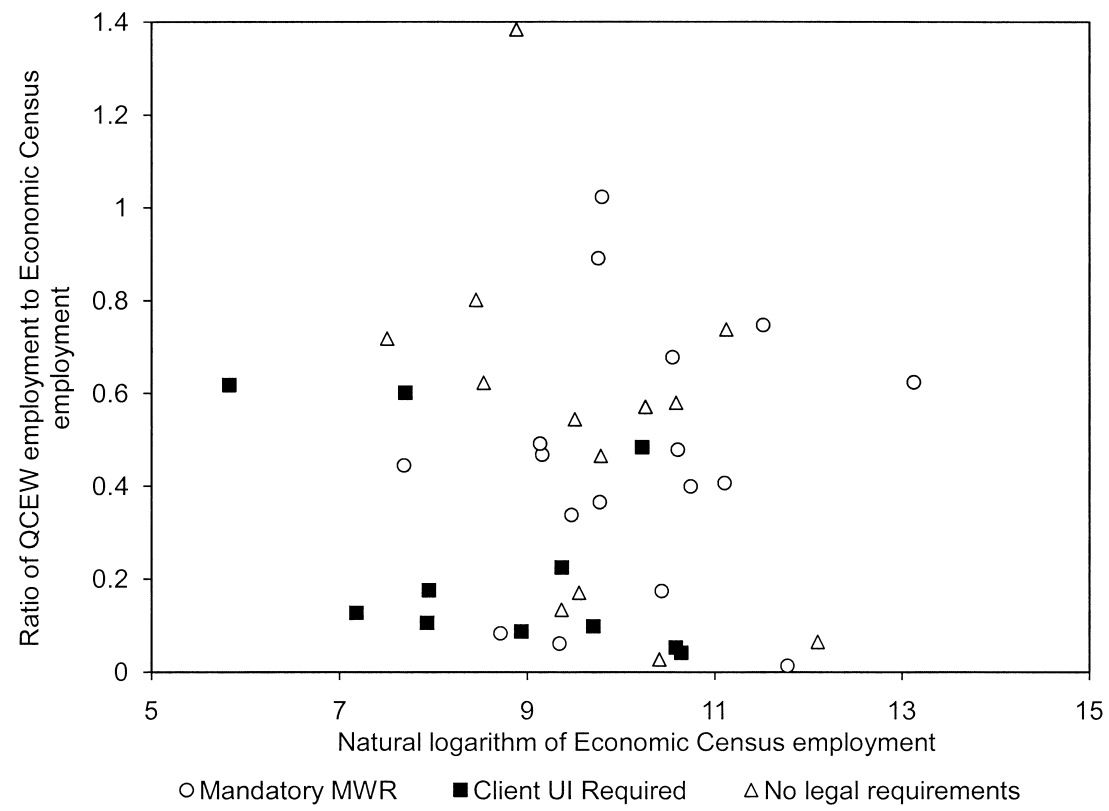

Fig. 7.2 Comparison of 2002 PEO employment 
ratio of QCEW to Economic Census estimates of PEO employment was 0.20 in states requiring PEOs to report under clients' UI accounts, compared to a ratio of 0.61 in states that did not have any legal requirements, and this difference was statistically significant at the 0.01 level. The ratio for states with mandatory work site reports for PEOs also was lower than for states with no legal requirements $(0.43$ vs. 0.61$)$, but this difference was not statistically significant. Given that the expected ratio in states requiring PEOs to report under the client's UI account number is close to zero, the fact that it is 0.20 implies that the reassignment by PEOs to their clients' accounts is far from complete. Only 25 percent of the states that required separate UI accounts for PEO clients had a ratio of less than 0.05 in 2002. If only the permanent staff of PEOs were reported, this ratio would be around 0.03 , which further indicates that reassignment to the clients' industry in these states is incomplete. Moreover, given that PEO employment figures in the QCEW and Economic Census should be the same in states with no legal requirement to use either a separate UI account or a multiple work site report, the fact that the ratio is 0.61 implies large discrepancies that cannot be explained by differences in reporting requirements still existing between these surveys. ${ }^{18}$ These discrepancies and the inconsistent treatment of PEO employees across states in the QCEW render it difficult to determine the amount of contracting out that is done through PEOs, as well as changes in PEO employment over time.

\subsection{Occupational Distribution in Employment Services}

Segal and Sullivan (1997) first noted a large shift in the distribution of employment within employment services toward manual occupations beginning in the 1990s. Paralleling our discussion of overall employment levels, we compare the levels of and trends in the occupational distribution of employment in employment services and its component industries as measured in the basic CPS, the Contingent Worker Supplements to the CPS, and the OES. ${ }^{19}$

We begin by comparing the occupational distribution of employment in all of employment services as measured in the outgoing rotation group samples of the basic CPS and in the OES. ${ }^{20}$ In figure 7.3 we present the

18. In combination with the state mandates, BLS has undertaken efforts to have PEOs report workers assigned to clients in the clients' industry. These efforts may have resulted in more of the data being assigned back to clients in recent years. However, there was no evidence of a decline in PEO employment prior to 2005 in the BLS state data that we examined (and on which we base the discussion in this chapter), and estimates of the current proportion of PEO employment assigned back to PEO customers in BLS data are not available.

19. None of the other surveys provides occupational information.

20. We also have compared the occupational distribution in the OES with that for the November CPS to be consistent with the timing of the OES survey. The comparison is not sensitive to seasonality, thus we report the CPS ORG because of its larger sample. 


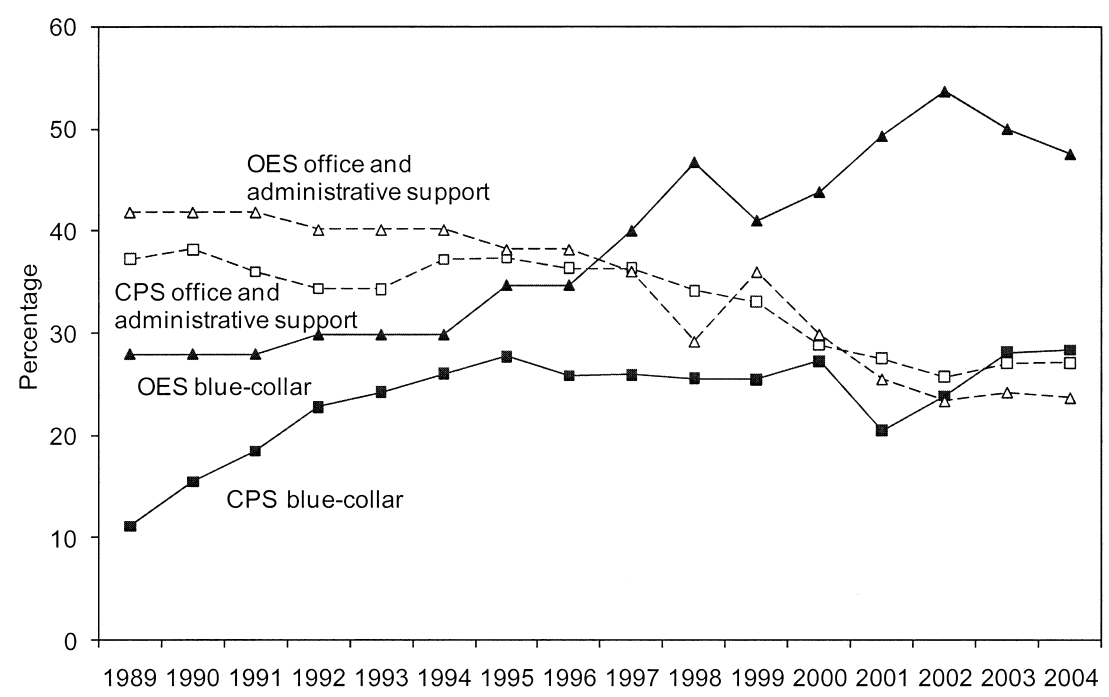

Fig. 7.3 Occupational distribution of employment, CPS vs. OES

employment shares for two broad occupational categories: office and administrative support occupations and blue-collar occupations. We define the latter as including six occupational categories, the largest of which are production occupations and helpers, laborers, and hand material movers. ${ }^{21}$ Both the CPS and the OES show a decline in the relative importance of clerical occupations in employment services, though the decline is more pronounced in the OES. Both the CPS and the OES record large growth in the relative importance of blue-collar occupations, but the timing is different. In the CPS the growth in the relative importance of blue-collar occupations occurs in the first half of the 1990s, whereas in the OES it is concentrated in the latter half of the 1990s and the 2000s. In addition, the share of employment in blue-collar occupations as measured in the OES is substantially higher than in the CPS in all years. We also have examined differences in the two series in the levels and trends within more narrowly defined occupations. The most pronounced differences in the two series are apparent for the lowestskilled manual occupations - helpers, laborers, and hand material movers (figure 7.4).

One might expect that the occupational distributions in the CWS and in the basic CPS would differ because, as discussed previously, reporting biases are more serious in the basic CPS and because individuals in the

21. We define blue-collar to include the following: supervisors of production occupations; repair and maintenance; construction and extraction; production; transportation and material moving; and helpers, laborers, and hand material movers. 


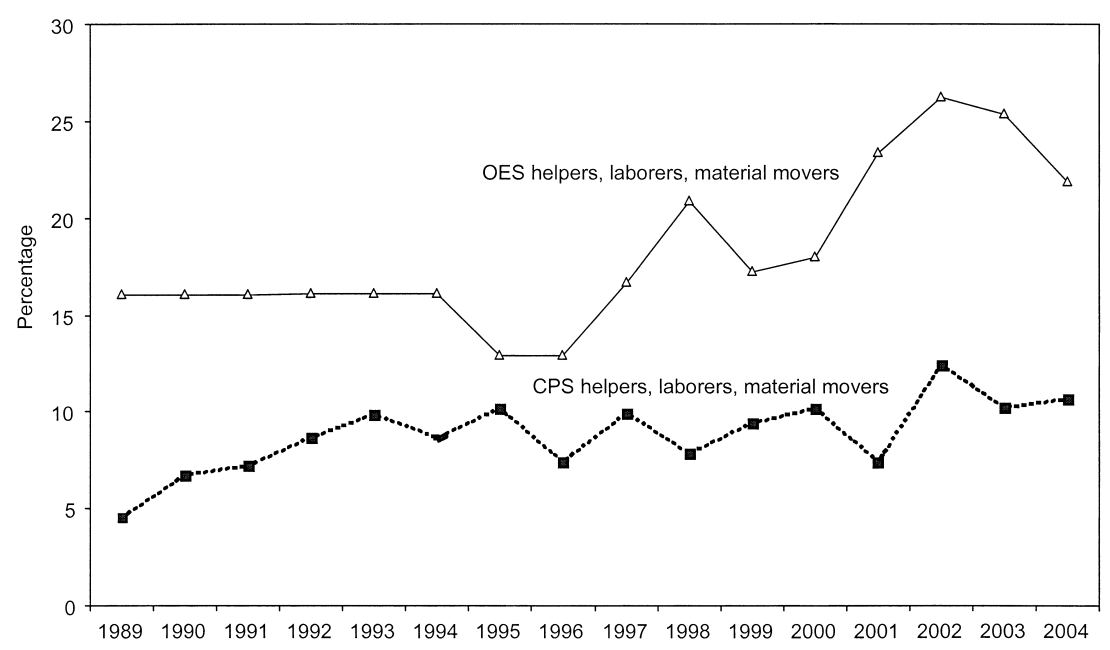

Fig. 7.4 Share of helpers, laborers, and hand material movers in employment services

CWS should only be employed by temporary help agencies, not by PEOs or employment placement agencies, which employ relatively fewer workers in blue-collar occupations. ${ }^{22}$ Yet discrepancies between the occupational distribution of employment found in the CWS and OES, displayed in figures 7.5 and 7.6, are similar to those between the basic CPS and the OES shown in figures 7.3 and 7.4. Figure 7.5 displays the employment shares in clerical and in blue-collar occupations among those identifying themselves as being paid by temporary help agencies in each of the five waves of the CWS. Also displayed are the percentages in these two broad occupation categories from the temporary help and PEO industries combined, using data from the OES from 1996 to 2004. Because establishments in the OES were classified into a broader industry category that included temporary help and PEOs prior to the introduction of NAICS in 2002, we report figures for the combined industry category. As is the case of the comparison with occupational distributions computed from the Current Population Survey Outgoing Rotation Group (CPS ORG), the dramatic increase in the relative importance of manual occupations apparent in the OES data from the 2000s is absent in the CWS data. Differences in levels and trends among the lowest-skilled workers are particularly striking in the two series (figure 7.6).

22. We are able to compare the occupational distributions of employment for PEO and temporary help establishments in the OES data beginning in 2002, and this comparison shows a considerably smaller percentage in production and other manual occupations in PEO establishments. 


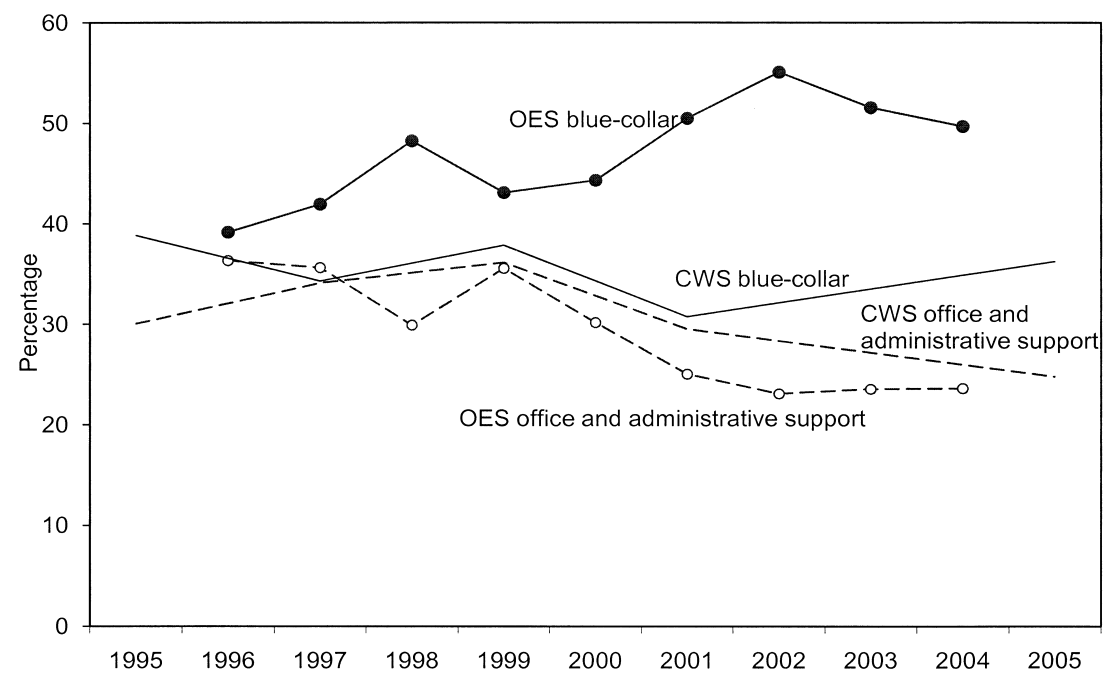

Fig. 7.5 Comparison of occupation distribution in OES (temp help and PEO) and CWS (temp help)

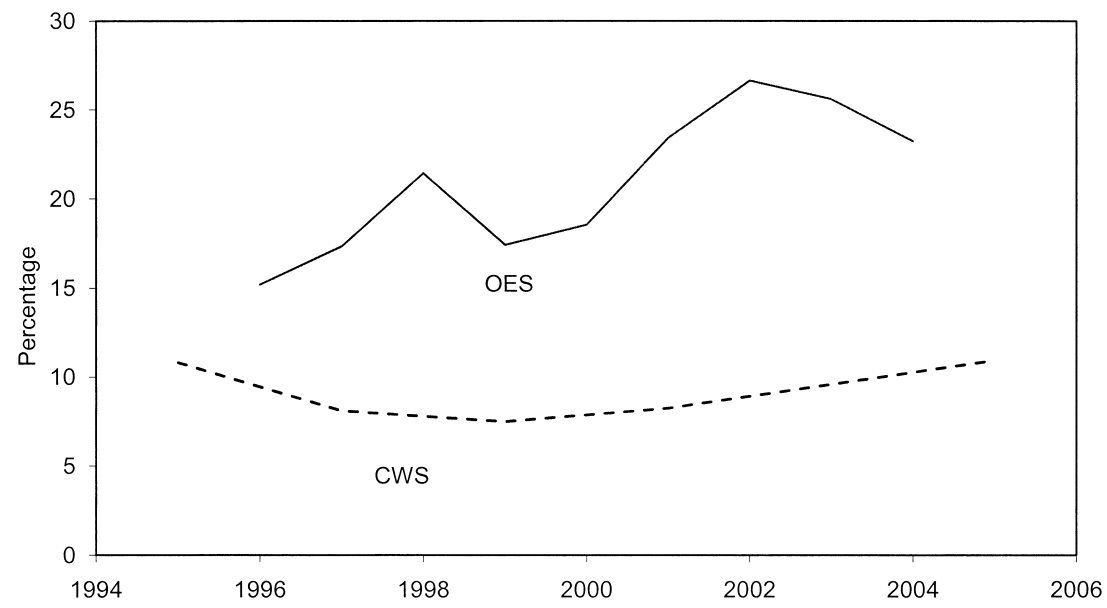

Fig. 7.6 Share of employment in helpers, laborers, and hand material movers occupations, OES (temp help and PEOs) and CWS (temp help)

Note: OES shows share of helpers, laborers, and hand material movers in temporary help and PEOs. CWS shows the share in that occupation category in temporary help. 


\subsection{Industry of Assignment}

Information on the occupational distribution of employment in employment services and on changes in that distribution may be suggestive of which industries are outsourcing to employment services. For example, the growth of production and other manual occupations in employment services has been taken as an indicator of the growth in manufacturers' use of outsourcing to employment services (Segal and Sullivan 1997). Direct information on industry use is needed to get precise estimates of how the growth of this contracting sector affects the industry distribution of employment, however, and such direct information is quite limited.

Estimates of the industry distribution of clients using temporary help agencies are available from the Contingent Worker Supplement (CWS). In each of the five waves of the CWS, information on the industry to which individuals were assigned was collected from workers identifying themselves as being on the payroll of a temporary help agency. Table 7.3 displays the distribution of industry of assignment in each of the five waves. ${ }^{23}$ In four of the waves, around 40 percent of temporary agency workers identified themselves in the CWS report as being assigned to manufacturing employers. In 2001, that figure abruptly dropped by about 10 percentage points. That decline mirrors a sharp decline in production workers in the temporary services industry in 2001 as recorded in the OES, which in turn likely reflects the recession and a tendency by manufacturers to reduce production employment first by cutting the temporary workforce.

Estimates of the distribution of industry of assignment for PEO workers are available from the Economic Census for 1992 and 1997. In both of those years, PEO establishments were asked to report the number of "leased employees by industry category of the client." According to those estimates, service industries were the largest users of PEOs, followed by transportation, communications, and utilities. Manufacturers accounted for an estimated 13 percent and 12 percent of PEO use in 1992 and 1997, respectively (table 7.4).

23. To identify industry of assignment, individuals in the CWS were first asked if the employer that they reported in the basic CPS was the temporary help agency or the employer to which they were assigned. Only if they indicated that it was the temporary help agency were they asked for the information about the employer to which they were assigned in the CWS. Apparently reflecting respondent confusion over the initial screening question, many who listed the temporary help agency in the basic CPS also indicated that this was the employer to which they were assigned, including a large number of production workers and workers in other manual occupations. As a result, about 20 percent were coded as being assigned back to the temporary help agency. Yet permanent agency staff only accounts for about 3 percent of payroll employment in temporary help agencies and temporary agencies would be expected to employ few if any workers in manual occupations as a part of their permanent administrative staff. For this reason, we deleted observations in which the employment services industry was coded as the industry of assignment in computing the industry of assignment distribution. 
Table 7.3

Distribution of industry of assignment, temporary help workers, CWS

\begin{tabular}{lrrrrr}
\hline Industry & 1995 & 1997 & 1999 & 2001 & 2005 \\
\hline Agriculture & 0.4 & 0.0 & 0.6 & 1.3 & 0.0 \\
Mining & 0.3 & 0.9 & 0.2 & 1.2 & 0.6 \\
Trade, transportation, and utilities & 15.0 & 14.3 & 13.6 & 14.6 & 13.9 \\
Construction & 3.6 & 3.2 & 3.3 & 4.1 & 3.8 \\
Manufacturing & 40.0 & 37.9 & 37.6 & 28.5 & 38.7 \\
Information & 5.1 & 6.8 & 6.5 & 5.9 & 1.5 \\
Financial activities & 9.5 & 11.2 & 10.0 & 9.2 & 0.0 \\
Professional and business services & 8.8 & 11.3 & 11.1 & 12.5 & 18.4 \\
Education services & 2.6 & 2.2 & 1.2 & 2.9 & 1.8 \\
Health care and social assistance & 7.0 & 6.7 & 9.5 & 11.4 & 11.9 \\
Arts, entertainment, and recreation & 0.4 & 0.2 & 0.6 & 1.4 & 0.0 \\
Accommodation and food services & 0.8 & 0.8 & 0.4 & 0.0 & 2.5 \\
Other services & 5.0 & 4.5 & 4.0 & 3.5 & 3.2 \\
Public administration & 1.6 & 0.0 & 1.6 & 3.7 & 3.9 \\
\hline
\end{tabular}

Notes: Calculations based on industry of assignment reported by those in CWS who indicate that they are paid by a temporary help agency. Individuals who report being assigned back to the employment services sector are excluded from the sample. All observations were weighted by CWS weights.

Table 7.4

Industry distribution of PEO clients, Economic Census

\begin{tabular}{lrr}
\hline Industry & 1992 & 1997 \\
\hline Agriculture, forestry and fishing & 0.9 & 1.3 \\
Mining & 0.4 & 0.1 \\
Construction & 8.2 & 11.6 \\
Manufacturing & 13.2 & 11.8 \\
Transportation, communication and utilities & 18.3 & 16.9 \\
Wholesale trade & 3.3 & 3.4 \\
Retail trade & 9.5 & 6.5 \\
Finance, insurance and real estate & 3.9 & 3.6 \\
Services & 30.9 & 34.4 \\
Other & 8.5 & 10.5 \\
\hline
\end{tabular}

In these two Economic Census years PEOs reported that only 1.3 percent of PEO employees were part of the PEO administrative structure. ${ }^{24}$

Using data from the OES and the CWS, we generate alternative estimates of the distribution of industry of assignment for PEO workers. To do so we assume that within occupations, the fraction assigned to an industry is the same for PEO workers as it is for temporary agency workers, where

24. In 2002 the Economic Census collected information on PEO use from client organizations, not from the PEOs. These 2002 estimates were not made public owing to concerns about data quality, and the Economic Census returned to its original format — asking for information about client industries from the PEOs_-in 2007. 
industry of assignment is measured in the CWS. For example, we assume that production workers in the PEO industry have the same probability of being assigned to manufacturing as production workers employed in temporary help agencies. We also assume that within occupations the CWS provides an unbiased estimate of the industry to which temporary agency workers are assigned, even if overall there is an undercount of temporary agency workers in the CWS. For instance, while temporary agency helpers and laborers appear to be underrepresented in the CWS even relative to other occupations, we assume that the temporary agency helpers and laborers who are identified in the CWS are neither more nor less likely to be assigned to manufacturing clients than is the case in the general population of temporary agency helpers and laborers. ${ }^{25}$ Based on these assumptions and using the occupational distribution of employment in PEO establishments, we estimate that between 23 and 29 percent of PEO workers were assigned to manufacturing from 2002 to $2004 .^{26}$

Estimates of the fraction of the employment services commodity used as an input in industries also are generated as part of the Bureau of Economic Analysis (BEA) input-output (I-O) benchmark tables. If the average price of an employment services worker does not vary across industries utilizing these workers, the BEA I-O figures represent an estimate of the fraction of employment services workers assigned to various industries. In the absence of data on industry of assignment for temporary help workers prior to the 1995 CWS, some researchers have used the BEA I-O figures to estimate the number of temporary help workers assigned to manufacturing and the growth of temporary workers in the manufacturing sector prior to the mid1990s (Estavão and Lach 1999a, 1999b).

However, the BEA I-O estimates are based on expenditure data pertaining to a broad set of contract workers and are collected from a subset of industries. In the 1997 benchmark I-O tables, estimates were derived from data collected in the Business Expenses Survey (BES), which is administered to companies in the wholesale, retail, and services sectors. Companies completing the survey were asked to report their expenditures on contract labor, defined as "persons who are not on your payroll but are supplied through a contract with another company to perform specific jobs (e.g., temporary help, leased employees)." It was assumed that companies answering this

25. We provide a more extensive discussion of our methodology for imputing employment services workers to client industries in Dey, Houseman, and Polivka (2008).

26 . While these estimates of the fraction assigned to manufacturing are roughly double those in the Economic Census, it is notable that the estimate of PEO workers in the Economic Census is comparably higher in these years, so that the total number of workers imputed to manufacturing is similar. Also, PEO employment almost doubled between 1997 and 2002 in the Economic Census, and it is unclear whether this growth was equally distributed across industries. If use of PEOs disproportionately grew in the manufacturing sector, the fraction of PEO workers assigned to manufacturing might be more comparable between the Economic Census and the imputation based on the 2002 to 2004 OES data. 
question reported expenditures on six types of contract services: (a) temporary help services, (b) employee leasing services, (c) security guards and patrol services, (d) office administrative services, (e) facility support services, and (f) nonresidential building cleaning services - and thus these services were treated as a bundled commodity. Data on industry output in each of these contract labor services industries came from the Economic Census and were aggregated to match the level of commodity aggregation assumed in the BES. The residual of the contract labor services not accounted for by industries surveyed in the BES was imputed to industries not surveyed in the BES based on their output shares. To generate I-O estimates at a more disaggregated commodity level, it was assumed that industries utilized all contract labor services in the same proportion. For instance, if an industry was estimated to use 10 percent of all contract labor services, it was assumed to use 10 percent of each of the component contract services.

The estimates from the BEA I-O tables on the industry distribution of the employment services commodity are markedly different from the estimates of the industry assignment distributions of temporary help and PEO workers from the CWS and from the Economic Census. Estimates based on the BEA I-O tables also seem inconsistent with the high proportion of blue-collar workers in the temporary help sector in the OES data (as documented previously), and the proportion of temporary help workers in the OES who were in production occupations specifically (Dey, Houseman, and Polivka 2008). For example, in the 1997 and 2002 benchmarks, the fraction of the employment services commodity assigned to manufacturing was under 5 percent. Although the input-output estimates, which are based on expenditure data, are not necessarily inconsistent with those from the Economic Census and the CWS, which are based on employment data, the size of the differences raises concerns about the accuracy of the Economic Census figures and at a minimum implies that the input-output figures are a poor indicator of the number of employment services workers outsourced to various industries.

\subsection{Evidence from the OES on Other Types of Domestic Outsourcing}

Although discrepancies in the data pertaining to employment services and its component industries are sometimes large across data sets, information about contracting out to this sector is rich relative to other types of domestic contracting out. Historically, firms have commonly outsourced many tasks, such as legal and construction services, to other entities. In this chapter, outside of employment services, our focus is not on the level of contracting out that occurs in the economy but rather on measuring how the patterns of domestic contracting out may have changed in recent years.

In the past, researchers have used data from a variety of sources to shed light on trends in other types of contracting out. Some have used growth 
of the business services sector as an indicator of growth in contracting out (Abraham 1988; Clinton 1997). One shortcoming of this approach is that, while one might expect that much of the growth in domestic outsourcing would accrue to establishments classified in the business services sector, contracting out is not limited to organizations classified in business services, and thus a study focused on business services may miss other important areas of outsourcing. Several nongovernment surveys have questioned private-sector businesses on trends in contracting out, and these surveys, conducted in the 1980s and 1990s, uniformly found strong indicators that businesses were increasing their domestic contracting out (Abraham 1988; Houseman 2001; Kalleberg, Reynolds, and Marsden 2003). These surveys, however, provide limited evidence on what functions businesses have outsourced.

Several studies have used evidence from various government surveys on the contracting out of selected services in selected industries. Abraham and Taylor (1996) relied on information in the 1986 to 1987 Industry Wage Surveys of thirteen manufacturing industries on firms' use of five business services(a) janitorial services, (b) machine maintenance services, (c) engineering and drafting services, (d) accounting services, and (e) computer services - at the time of the survey (1986-1987), and retrospectively in 1983 and 1979. Using this information, Abraham and Taylor constructed an estimate of a change over time in the proportion of manufacturing firms that contracted out for the provision of the service. Bartel, Lach, and Sicherman (2005) used the Census of Manufactures to obtain an estimate of an increase in the amount of contracting out by manufacturers of eight selected services. ${ }^{27}$ They estimated that the manufacturing sector's spending on these outsourced services more than doubled between 1992 and 1997, increasing from 4.25 percent of total value added in 1992 to 10.68 percent in 1997. Using expenditure data from the 1987, 1992, and 1997 Truck Inventory and Use Surveys conducted by the Census Bureau as part of the Census of Transportation, Baker and Hubbard (2002) examined trends in the contracting out of trucking services. They found a decrease in the share of for-hire trucking between 1987 and 1992 but an increase in the use of for-hire trucking between 1992 and 1997.

The Contingent Worker Supplements to the CPS were designed to fill many of the information gaps on contracting out. In the survey, individuals were identified as contract workers according to their answers to the question, "Some companies provide employees or their services to others under contract. A few examples of services that can be contracted out include security, landscaping, or computer programming. Did you work for a company

27. The Census of Manufactures collects information on the dollar amount of purchased services that manufacturing firms spend on eight items: (a) repair of buildings and other structures, (b) repair of machinery, (c) communication services, (d) legal services, (e) accounting and bookkeeping services, (f) advertising, (g) software and data processing services, and (h) refuse removal. 
that contracted out you or your services last week?" The share of workers identifying themselves as contract workers was relatively small, about 1.5 percent, and displayed no trend increase over the five CWS waves conducted from 1995 to $2005 .^{28}$ One reason may be that employees of one company that contracts out their services to another organization may not be called contract workers and may not know for whom their work is being done, particularly if they are performing tasks for a variety of client companies off-site. For example, advertising agencies typically provide services to many clients under contract, but their employees may not consider themselves employees of a contract company. ${ }^{29}$

We use the longitudinal data that we constructed from the OES on occupation by industry to shed additional light on trends in domestic outsourcing in selected occupations. The strength of the OES lies in the detailed information collected on the occupational structure within industries. Thus, with some prior information about which occupations are being contracted out and the industry or sector to which the jobs are being outsourced, we can build longitudinal data at the level of detail needed to observe whether the trend in the industry structure of employment is consistent with a growth in contracting out of that occupation. Because of the change from SIC to NAICS industry classification, which was implemented in 2002 in the OES, we only report data for the years 1989 through 2001 in this part of our analysis.

To identify occupations that were contracted out, we selected the most common occupations held by those who identified themselves as working for a company that contracted out their services in the five waves of the CWS. Although individuals likely underreport contracting out in the CWS, the CWS should be a useful tool for identifying occupations that are frequently outsourced and the contract industries in which they are employed. We supplemented this list in one instance with case-study evidence of outsourcing. ${ }^{30}$

Using this process, we examine trends in the industry structure of employment for six occupations: (a) school bus drivers, (b) truck drivers, (c) janitors, (d) security guards, (e) computer occupations, and (f) accountants. Figure 7.7 displays total employment in the indicated occupation, employment of the occupation in what we identify as the contract sector, and the share of the occupation's employment in the contract sector, all from 1989 to 2001.

The case of school bus drivers offers a simple example of how the OES can be helpful in identifying the growth of contracting out in a particular

28. The share of workers identifying themselves as contract workers who were assigned primarily to one client's work site was about a half percentage point.

29. Indeed, the questions on the CWS pertaining to contract workers were primarily designed to capture workers performing tasks at a single client company's work site. Follow-up questions in the CWS asked individuals who initially identified themselves as contract workers whether they worked at the customer work site and whether they worked at more than one work site. Thus, the CWS is not ideally suited for examining broader trends in domestic outsourcing.

30 . We include school bus drivers on the basis of case-study evidence in Erickcek, Houseman, and Kalleberg (2003). 

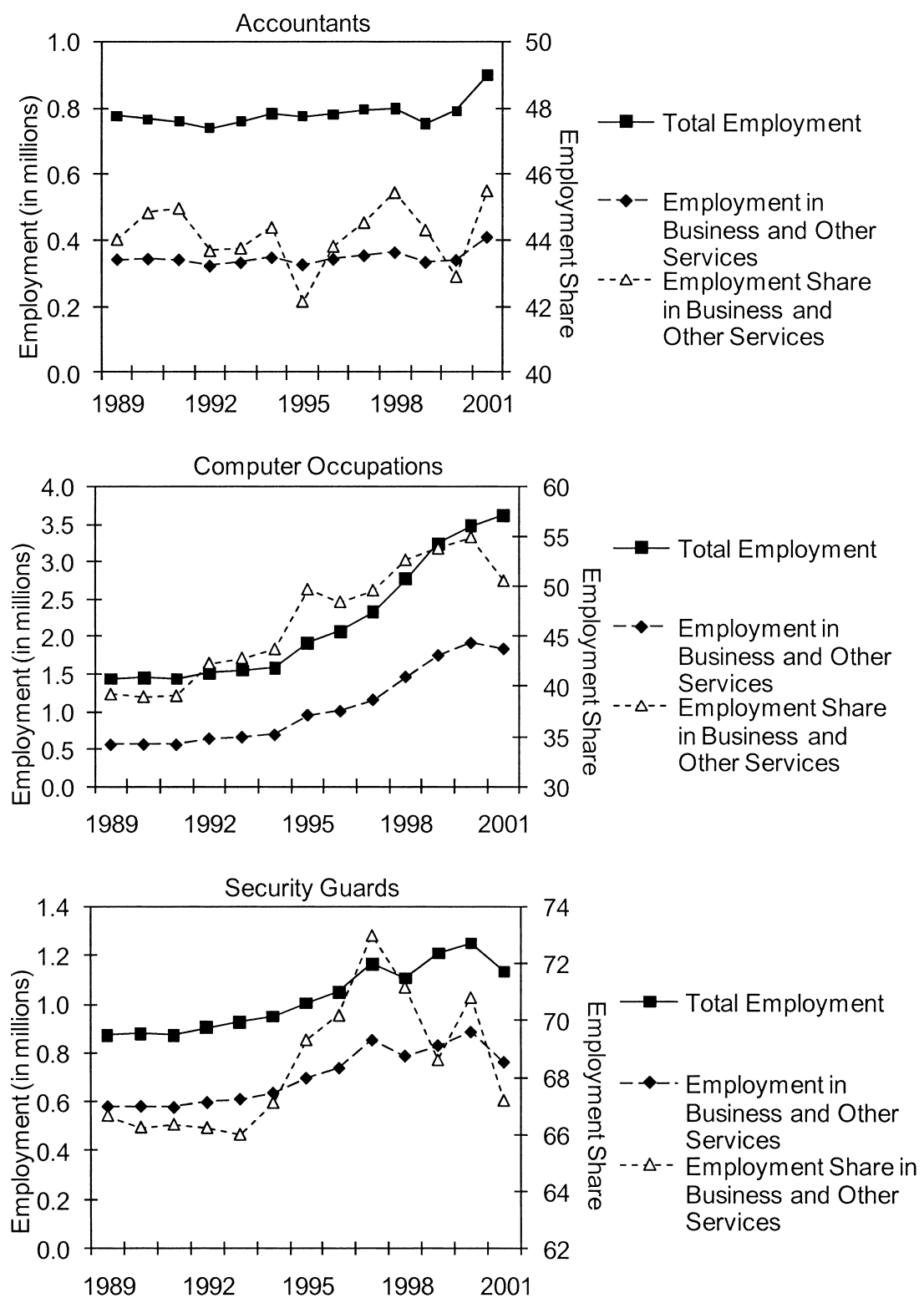

Fig. 7.7 Trends in the industry structure of employment, selected occupations

occupation. School bus drivers are, for all intents and purposes, employed by school systems (public or private), or by a contract bus service industry within the trade and transportation sector when the service is outsourced by schools. Case-study evidence that school systems have increasingly contracted out bus services (Erickcek, Houseman, and Kalleberg 2003) is borne 

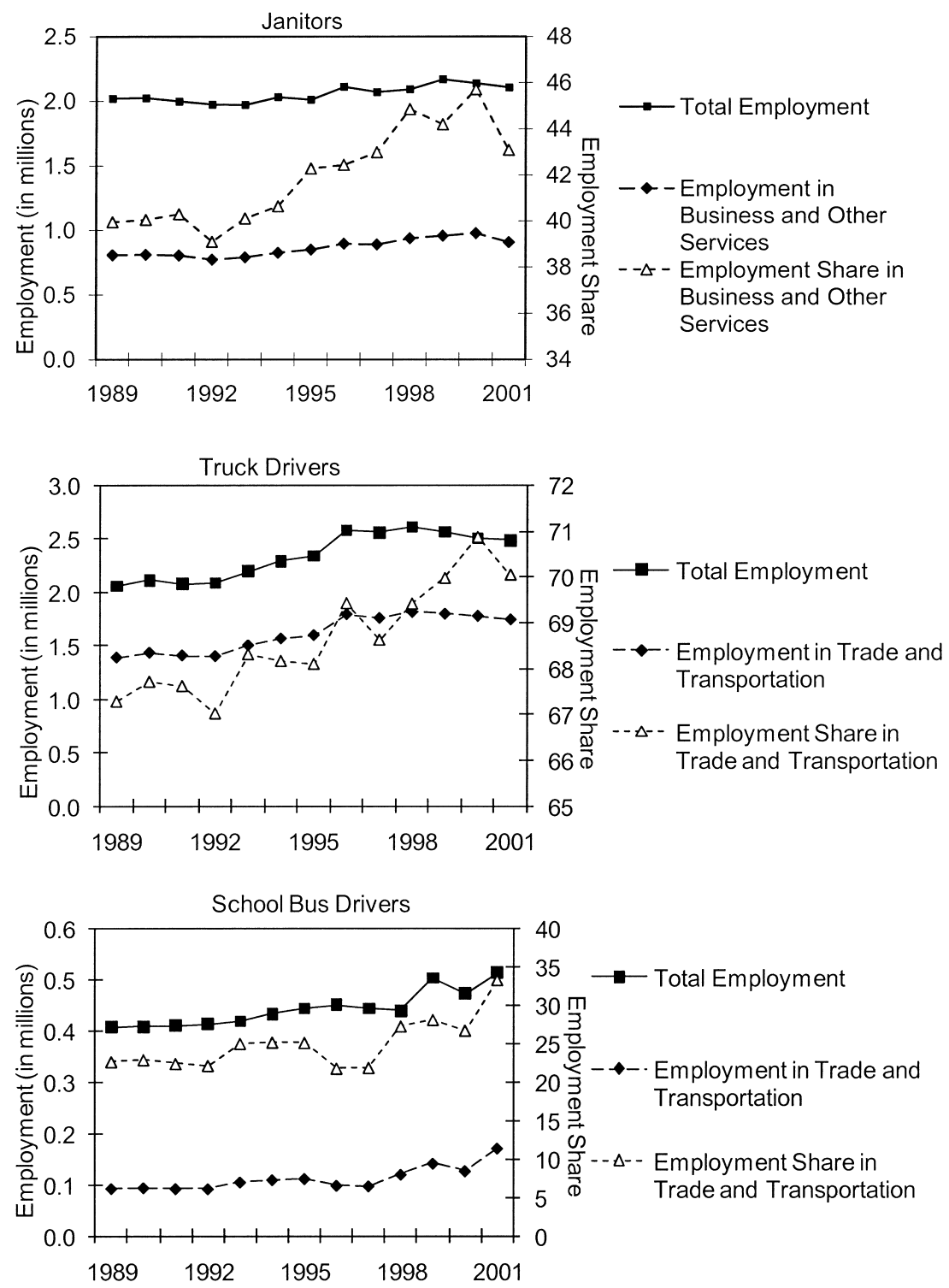

Fig. 7.7 (cont.)

out in the OES data. The share of school bus drivers employed in the trade and transportation sector grew from 23 percent in 1989 to 33 percent in 2001, according to OES data.

We also examine trends in the contracting out of truck driver services. The CWS identified this occupation as one that is commonly contracted out, and 
the OES data indicate that the share of truck drivers in the trade and transportation sector grew by a modest 3 percentage points from 1989 to 2001 . This finding is consistent with evidence of a growth in contracting out of trucking services from 1992 to 1997, reported in Baker and Hubbard (2002).

In the other four occupations - janitors, security guards, computer occupations, and accountants - we look for growth in the share of workers in business services as an indicator of growth in contracting out in that occupation, and we find evidence of growth in contracting out in two. According to OES data, the share of workers in computer occupations employed in business services increased dramatically, from 39 percent in 1990 to over 50 percent a decade later. ${ }^{31}$ Growth in the share of janitors employed in business services increased 3 to 6 percentage points over the same period.

Our examination of OES data overall shows considerable evidence of growth in contracting out in the occupations identified as the most commonly outsourced occupations in the CWS, in spite of the fact that there was no apparent trend increase of contract workers in the CWS. We hypothesize that small samples in the CWS for these workers and confusion among respondents over whether their work is contracted out explains why growth in contracting out is not apparent in the household survey, even when it is in establishment data.

Use of the OES to detect trends in outsourcing has some limitations that should be noted. First, except in rather clear-cut cases (such as school bus drivers) in which the industry engaging in the outsourcing can be easily identified, increases in the share of an occupation employed in a sector associated with contracting out should be interpreted with some caution. An increase in the share of workers in a particular occupation in the contract sector may reflect an increase in the propensity of firms to contract out that occupation. Alternatively, it could reflect a general change in the industrial mix in the economy, with a decline in the share of industries that historically have performed the task in-house and a growth in the share of industries that historically have outsourced the task. For example, the growth in the share of truck drivers in the transportation sector could reflect an increase in contracting out of trucking services by manufacturers and companies in other sectors; alternatively, it could reflect the decline of manufacturing, which employs relatively more truck drivers than other sectors of the economy that are expanding. In addition, the OES data is useful for detecting growth in contracting out only in cases in which an industry that employs the contract workers is distinct from the industry engaging in the contracting out. Much outsourcing may occur within an industry, and such intra-industry contracting out would be difficult to detect in the OES data. Nevertheless, in view of

31. The drop in the share of computer operators employed in business services between 2000 and 2001 could reflect the recession in 2001 or reduced demand for contract computer workers after the start of the new millennium. 
the absence of comprehensive data on contracting out, the OES provides a useful tool in many circumstances for better understanding changes in patterns of domestic outsourcing and their consequences for the industry distribution of employment.

\subsection{Conclusions}

Data limitations greatly restrict the ability of researchers to track changing patterns of contracting out and study their implications for the structure of employment in the economy. Fairly extensive data do exist for employment services, a sector in which almost all of the employment represents contracting out. However, employment services only provides a partial picture of contracting out in the United States, and the information provided by various sources of data on the employment services sector is often inconsistent. The Contingent Worker Supplements include a question that allows individuals to identify themselves as working for an employer that contracts out their services, but questions in the CWS pertaining to contract workers are designed primarily to capture situations in which contract workers work at one client's work site. This focus, coupled with likely respondent confusion over what is meant by contract services, limits the usefulness of the CWS in picking up broader trends in domestic outsourcing. The Bureau of Economic Analysis draws upon a wide range of government and industry data sources to construct a comprehensive input-output structure for the economy. These estimates, however, are only as good as the underlying data, and, particularly in emerging areas of outsourcing, data may be thin. In addition, input-output estimates are typically based on expenditure data, which may not adequately measure the extent to which industries utilize workers from the contract sector. As was illustrated in the case of employment services, information from input-output tables may be a poor indicator of the extent to which various industries contract out jobs to the sector of interest.

As a first step toward improving our understanding of domestic contracting out, it would be very helpful if the statistical agencies-BLS, BEA, and the Census Bureau - provided better documentation of selected statistics and thereby allowed users to assess the quality of the data and their suitability for measuring domestic outsourcing. Specifically, the QCEW program at BLS could better document its treatment of PEOs, including, for current and past estimates, the proportion of PEO employment in each state that was assigned back to client industries and the methodology that was used to make this assignment. Moreover, to enhance our understanding of PEOs, the QCEW could publish two sets of industry employment estimates: one that includes all PEO employment in the PEO industry (without any of it being assigned back to clients), and a second in which PEO employees have been reassigned to client industries.

In addition, the Census Bureau could provide data quality measures for 
specific questions about PEOs and their clients, including response rates and information about imputation methodologies for missing data. It also would be useful to data users if the Census Bureau provided more complete documentation of the instructions and methodologies used for PEOs in the manufacturing and service components of the Economic Censuses. A comparison of BLS's establishment list and the Census Bureau's establishment list specifically for PEOs also could help illuminate whether the difference between the QCEW and Economic Census estimates of the number of employment sector workers results from differences in industry classification of the PEOs, variation in PEO employment over time, or different treatment of PEO employment by the two surveys.

With regard to the BEA, its input-output tables, and its annual benchmark tables, there would be great value in the BEA documenting the sources, age, and quality of the underlying data and the methodologies used to generate the estimates. This documentation could include the number of observations on which an estimate is based and its standard error, so that data users can assess the quality of the data directly. Alternatively, if releasing this information is not possible for confidentiality reasons, the BEA could provide to the public its own assessment of the quality of the data, indicating in particular when an estimate is based on good data sources with an adequate number of observations and when an estimate is based on poorer quality or thinner underlying data.

In order to use BEA input-output tables or the BEA's annual benchmark tables to study domestic outsourcing or offshore outsourcing as has been suggested by some authors (Kurz and Lengermann 2008; Yuskavage, Strassner, and Medeiros 2008), the underlying data need to be reliable, or at least a measure of their reliability needs to be known. Furthermore, the quality of the input-output estimates and the underlying data will influence other economic measures, such as multifactor productivity estimates, that assume employers' contracting out expenditures are adequately measured.

In addition to providing better documentation with sufficient resources, the BLS and Census ideally would collect more complete and better quality information about the extent of and reasons behind companies' outsourcing practices. Collecting such information at the company rather than at the establishment level, we believe, would be preferable because it would avoid counting domestic, intracompany exchanges as outsourcing. The information collected at the company level might include expenditure data on additional specific contract services and on the total of all contracting, the organizations' reasons for outsourcing, and the names of companies from which contracted services were obtained. Information on why companies contract out work would help to answer questions about whether and where contract work can be expected to expand, how contract work may vary over the business cycle, and the implications of domestic outsourcing 
for workers. ${ }^{32}$ Some information on contract workers and the industries to which they are assigned might be best obtained from the contract companies.

As a starting point for the collection of information on organizations' use of contract workers, information about the clients of staffing agencies could be collected from the staffing agencies. Alternatively, organizations' use of workers from staffing services could be obtained from the organizations. The BLS did developmental work for a supplement to the CES that would have asked establishments about their use of temporary help workers, PEOs, and independent contractors. However, because of a lack of funding, this supplement was never administered during actual data collection.

Finally, resources permitting, a matched employer-employee survey could be conducted to shed light on the discrepancies between the CPS and CES estimates of temporary help and PEO workers. Matched employer-employee data also would provide more information about the effects of companies contracting out practices on specific types of workers and differences in employees' and employers' perceptions of workplace practices and expectations about the security of employment. Matching data collected in the Contingent Worker Supplement to establishment data via the Longitudinal Employer-Household Dynamics (LEHD) program could help to provide insights into the discrepancies observed through 2005, although the sample sizes may be small for some types of workers and to examine discrepancies in temporary help employment measures in the future, the CWS would have to be repeated. Furthermore, a new matched employer-employee survey would be needed to obtain information about contracting out more broadly.

Although, given resource constraints, a comprehensive documentation of changing patterns of domestic outsourcing and its employment effects probably is not feasible in the near term, existing data could be used to flag major shifts in outsourcing patterns. We suggest that OES data can be a useful, complementary tool to detect such shifts. In simple cases like that of school bus drivers, the shift of workers in a particular occupation from one industry to another in the OES represents a direct measure of outsourcing. In other cases, shifts in the industry composition of occupational employment may be valuable indicators of changing outsourcing patterns that could be followed up with targeted surveys where deemed desirable. The sector of employment services offers a sobering example, however, of how difficult it can be to obtain information on the extent of outsourcing and the industries engaging in the outsourcing, even when considerable resources are expended on collecting this information.

32. Currently, as part of the Mass Layoff Statistics (MLS) program sponsored by the BLS, establishments that have an extended mass layoff (defined as a layoff of fifty or more people during a five-week period that lasts thirty days or longer) are asked whether this layoff results from the establishment moving work to another establishment domestically or internationally. Using this information, it is possible to construct a measure of the number of individuals involved in an extended mass layoff that stems from domestic contracting out. However, this measure is restricted to contracting out that results in substantial job losses; it does not capture outsourcing that results in no or only limited job losses. 


\section{Appendix}

\section{Table 7A.1}

Occupation titles

Management, business, and financial operations occupations

Architecture and engineering occupations

Life, physical, and social science occupations

Computer and mathematical occupations

Healthcare practitioners and technical occupations

All other professional, paraprofessional, and technical occupations

Sales and related occupations

Office and administrative support occupations

Protective service occupations

Food and beverage preparation and service occupations

Cleaning and building service occupations

All other service and agricultural, forestry, fishing, and related occupations

First-line supervisors of production, construction, maintenance, and related workers

Installation, maintenance, and repair occupations

Construction and extraction occupations

Production occupations

Transportation and material moving occupations

Helpers of production workers and laborers and hand material movers

Table 7A.2

Industry titles

Mining

Trade, transportation, and utilities

Construction

Manufacturing

Information

Financial activities

Professional and business services

Education services

Health care and social assistance

Arts, entertainment, and recreation

Accommodation and food services

Employment services

Other services

Federal government

State government

Local government

\section{References}

Abraham, K. G. 1988. Flexible staffing arrangements and employers' short-term adjustment strategies. In Employment, unemployment, and labor utilization, ed. R. A. Hart, 288-311. Boston: Unwin Hyman.

1990. Restructuring the employment relationship: The growth of market- 
mediated work arrangements. In New developments in the labor market: Toward a new institutional paradigm, ed. K. G. Abraham and R. B. McKersie, 85-119. Cambridge, MA: MIT Press.

Abraham, K. G., and J. Spletzer. 2007. Are the new jobs good jobs? Paper presented at NBER CRIW conference on Labor in the New Economy. Bethesda, MD, November 16-17.

Abraham, K. G., and S. K. Taylor. 1996. Firms' use of outside contractors: Theory and evidence. Journal of Labor Economics 14 (3): 394 424.

Autor, D. H. 2001. Why do temporary help firms provide free general skills training? Quarterly Journal of Economics 116 (4): 1409-48.

. 2003. Outsourcing at will: The contribution of unjust dismissal doctrine to the growth of employment outsourcing. Journal of Labor Economics 21 (1): 1-42.

Autor, D. H., F. Levy, and R. J. Murnane. 1999. Skills training in the temporary help sector: Employer motivations and worker impacts. Final report. Washington, DC: U.S. Department of Labor, Employment and Training Administration.

Baker, G. P., and T. N. Hubbard. 2002. Make versus buy in trucking: Asset ownership, job design and information. NBER Working Paper no. W8727. Cambridge, MA: National Bureau of Economic Research, January.

Bartel, A., S. Lach, and N. Sicherman. 2005. Outsourcing and technological change. NBER Working Paper no. 11158. Cambridge, MA: National Bureau of Economic Research, February.

Clinton, A. 1997. Flexible labor: Restructuring the american work force. Monthly Labor Review 120 (8): 3-27.

Cohany, S. R. 1996. Workers in alternative employment arrangements. Monthly Labor Review 119 (10): 31-45.

Davis-Blake, A., and B. Uzzi. 1993. Determinants of employment externalization: A study of temporary workers and independent contractors. Administrative Science Quarterly 38 (2): 195-223.

Dertouzos, J. N., and L. A. Karoly. 1992. Labor market responses to employer liability. RAND Corporation Document R-3989-ICJ. Santa Monica, CA: RAND Institute for Civil Justice.

Dey, M., S. Houseman, and A. Polivka. 2008. Manufacturers' outsourcing to employment services. Upjohn Institute for Employment Research Working Paper no. WP07-132. Available at: http://www.upjohninstitute.org/publications/wp/ 07-132.pdf.

Erickcek, G., S. Houseman, and A. Kalleberg. 2003. The effects of temporary services and contracting out on low-skilled workers: Evidence from auto suppliers, hospitals, and public schools. In Low-wage American: How employers are reshaping opportunity in the workplace, ed. E. Appelbaum, A. Bernhardt, and R. J. Murnane, 368-406. New York: Russell Sage Foundation.

Estavão, M., and S. Lach. 1999a. Measuring temporary labor outsourcing in U.S. manufacturing. NBER Working Paper no. 7421. Cambridge, MA: National Bureau of Economic Research, November.

1999b. The evolution of the demand for temporary help labor supply in the United States. NBER Working Paper no. 7427. Cambridge, MA: National Bureau of Economic Research, December.

Golden, L. 1996. The expansion of temporary help employment in the U.S., 19821992: A test of alternative economic explanations. Applied Economics 28 (9): $1127-41$.

Golden, L., and E. Appelbaum. 1992. What was driving the 1982-1988 boom in temporary employment-preference of workers or decisions and power of employers? American Journal of Economics and Sociology 51 (4): 473-93. 
Government Accountability Office (GAO). 2006. Employment arrangements: Improved outreach could help ensure proper worker classification. GAO-06-656. Washington, DC: GAO.

Hachen, D. S., Jr. 2004. Contracting out work in the 1990s. South Bend, IN: University of Notre Dame, Department of Sociology. Working Paper.

Hamermesh, D. 1993. Labor demand. Princeton, NJ: Princeton University Press.

Hart, R. A. 1984. The economics of non-wage labour costs. London: George Allen and Unwin.

Houseman, S. 1998. Labor standards in alternative work arrangements. Labor Law Journal 49 (7): 1135-41.

2001. Why employers use flexible staffing arrangements: Evidence from an employer survey. Industrial and Labor Relations Review 55 (1): 149-70.

Houseman, S., A. Kalleberg, and G. Erickcek. 2003. The role of temporary help employment in tight labor markets. Industrial and Labor Relations Review 57 (1): 105-27.

Houseman, S., and A. Polivka. 2000. The implications of flexible staffing arrangements for job security. In On the job: Is long-term employment a thing of the past? ed. D. Neumark, 427-62. New York: Russell Sage Foundation.

Kalleberg, A. L., J. Reynolds, and P. V. Marsden. 2003. Externalizing employment: Flexible staffing arrangements in U.S. organizations. Social Science Research 32 (4): 525-52.

Katz, B. 1999. What a PEO can do for you. Journal of Accountancy 188 (1): 57-61.

Katz, L. F., and A. B. Krueger. 1999. The high-pressure U.S. labor market of the 1990s. Brookings Papers on Economic Activity, 1999 (1): 1-87.

Klass, B. S., T. W. Gainey, J. A. McClendon, and H. Yang. 2005. Professional employer organizations and their impact on client satisfaction with human resource outcomes: A field study of human resource outsourcing in small and medium enterprises. Journal of Management 31 (2): 234-54.

Krueger, A. B. 1993. How computers have changed the wage structure: Evidence from microdata, 1984-1989. Quarterly Journal of Economics 108 (1): 33-60.

Kurz, C., and P. Lengermann. 2008. Outsourcing and U.S. economic growth: The role of imported intermediated inputs. Paper presented at the 2008 World Congress on National Accounts and Economic Performance Measures for the Nations. Arlington, VA, May 12-17.

Lautsch, B. A. 2002. Uncovering and explaining variance in the features and outcomes of contingent work. Industrial and Labor Relations Review 56 (1): 23-43.

Lee, D. R. 1996. Why is flexible employment increasing? Journal of Labor Research 17 (4): 543-53.

Lenz, E. A. 1996. Flexible employment: Positive work strategies for the 21st century. Journal of Labor Research 17 (4): 663-81.

Masters, J. K., and G. Miles. 2002. Predicting the use of external labor arrangements: A test of the transaction costs perspective. Academy of Management Journal 45 (2): 431-42.

Mehta, C., and N. Theodore. 2001. The temporary staffing industry and U.S. labor markets: Implications for the unemployment insurance system. Center for Urban Economic Development, University of Illinois at Chicago.

Mehta, C., S. Braum, N. Theodore, and L. Bush. 2003. Workplace safety in Atlanta's construction industry: Institutional failure in temporary staffing arrangements. Paper presented at America's Workforce Network Research Conference. Washington, DC, June 25-26.

Ono, Y., and D. Sullivan. 2006. Manufacturing plants' use of temporary workers: An 
analysis using Census micro data. WP 2006-24. Chicago: Federal Reserve Bank of Chicago.

Polivka, A. E. 1996a. Are temporary help agency workers substitutes for direct hire temps? Searching for an alternative explanation for the growth of the temporary help industry. Washington, DC: U.S. Department of Labor, Bureau of Labor Statistics. 1996b. Contingent and alternative work arrangements, defined. Monthly Labor Review 119 (10): 3-9.

Segal, L. 1996. Flexible employment: Composition, and trends. Journal of Labor Research 17 (4): 527-42.

Segal, L. M., and D. G. Sullivan. 1995. The temporary work force. Economic Perspectives, A Review from the Federal Reserve Bank of Chicago 19 (2): 2-19.

- 1997. The growth of temporary service work. Journal of Economic Perspectives 11 (2): 117-36.

Theodore, N., and J. Peck. 2002. The temporary staffing industry: Growth imperatives and limits to contingency. Economic Geography 78 (4): 463-93.

Topel, R. H. 1982. Inventories, layoffs, and the short-run demand for labor. American Economic Review 72 (4): 769-87.

U.S. Bureau of Labor Statistics (BLS). 1988. Industry wage survey: Temporary help supply 1987. Bulletin 2313. Washington, DC: BLS.

Yuskavage, R. E., E. H. Strassner, and G. W. Medeiros. 2008. Outsourcing and imported inputs in the U.S. economy: Insights from integrated economic accounts. Paper presented at the 2008 World Congress on National Accounts and Economic Performance Measures for the Nations. Arlington, VA, May 12-17.

\section{Comment Daniel G. Sullivan}

Dey, Houseman, and Polivka have brought together in one place virtually all that is known about the overall extent of and trend in contracting out work in the United States. They did this in admirable fashion by carefully combining and comparing numerous data sources. However, despite their careful and creative work, we are left with rather incomplete knowledge of this important phenomenon. Currently available data collection programs simply are not well designed for studying the general phenomenon of contracting out. Moreover, even when significant data collection efforts have been devoted to studying portions of the contracting out phenomenon, as with employment by temporary help agencies, alternative data sources yield very different results. Clearly, the statistical agencies have a great deal more work to do if we are to adequately understand the collection of employment practices known as contracting out.

There are two categories of reasons to be interested in the work presented by the authors. The first category relates to its implications for the function-

Daniel G. Sullivan is executive vice president and director of research at the Federal Reserve Bank of Chicago. 